This PDF is a selection from a published volume from the National Bureau of Economic Research

Volume Title: Producer Dynamics: New Evidence from Micro Data

Volume Author/Editor: Timothy Dunne, J. Bradford Jensen, and Mark J. Roberts, editors

Volume Publisher: University of Chicago Press

Volume ISBN: 978-0-226-17256-9

Volume URL: http://www.nber.org/books/dunn05-1

Conference Date: April 8-9, 2005

Publication Date: January 2009

Chapter Title: Producer Dynamics in Agriculture: Empirical Evidence

Chapter Author: Mary Clare Ahearn, Penni Korb, Jet Yee

Chapter URL: http://www.nber.org/chapters/c0493

Chapter pages in book: (369 - 391) 


\title{
Producer Dynamics in Agriculture Empirical Evidence
}

\author{
Mary Clare Ahearn, Penni Korb, and Jet Yee
}

\subsection{Introduction}

The U.S. farm sector is characterized by a great deal of heterogeneity. This heterogeneity has been well-documented through Censuses of Agriculture (beginning in 1840) and a variety of surveys (such as the annual U.S. Department of Agriculture [USDA] farm household surveys, initiated in 1984'). A major indicator of the heterogeneity within the farm sector is the size distribution of farms. One reason for the heterogeneity in farm sizes are the multiple objectives of producers, which in addition to profitmaking, include a high-quality rural lifestyle. More than three-quarters of farms have gross farm sales less than $\$ 50,000$ and, on average, lose money farming. Other common indicators that exhibit extensive heterogeneity in the structure of the industry include the type of commodity specialization, the extent of commodity diversification, and various farm household characteristics, such as major occupation of the farm operator.

While the traditional aggregate indicators capture the heterogeneity of agriculture, they also provide a picture of relative stability over time. According to the most recent Census of Agriculture (2002), there were about 2.1 million farms in the United States (USDA 2004a). That count is only 8

Mary Clare Ahearn is an agricultural economist with the Economic Research Service, U.S. Department of Agriculture. Penni Korb is an agricultural economist with the Economic Research Service, U.S. Department of Agriculture. Jet Yee was an economist with the Economic Research Service, U.S. Department of Agriculture, when this research was done.

The authors would like to thank Spiro Stefanou for his helpful comments. The views expressed are those of the authors and do not necessarily represent the policies or views of USDA.

1. Since 1996, the survey is the Agricultural Resource Management Survey. Previously, it was the Farm Costs and Returns Survey (USDA 2004b). 
percent less than thirty years ago, and, in fact, there has been a slight increase in farm numbers in the last decade. Similarly, the average acres in a farm in 1978 were 449, compared to 441 in 2002 . However, this relative stability in the number of farms and average size in acres masks a great deal of dynamics of entry and exit of farms, as well as changing of farm size for the new and continuing farms.

Unlike the cross-sectional heterogeneity and the aggregate changes in farm characteristics over time, relatively little has been known about the dynamics of the changing U.S. farm sector. As is true for other industries in the economy until recently, this is largely because of the lack of access to a panel data set. Early research in the United States on farm turnovers relied on county-level estimates of farm exits (e.g., Goetz and Debertin 2001) and national analysis (e.g., Barkley 1990). Research that relies on panel data to examine turnover has largely focused on small geographical areas. For example, following the strained financial conditions of the 1980s, the USDA supported small area studies of farm exits in Wisconsin and Kentucky (Bentley et al. 1989; Bentley and Saupe 1990; Wu 1997). Foltz (2004) is a more recent example of a small area study, which focused on farm exits in Connecticut and the role of a government program to support dairy producers. The longitudinal file we employ in this chapter has its roots in a joint effort during the 1980s by the Bureau of the Census and the Economic Research Service to link 2 Censuses of Agriculture. Early applications using this data file focused on forecasting future changes in the structure of farming (e.g., Edwards, Smith, and Peterson 1985). A recent study using the Census of Agriculture longitudinal file focused on explaining the determinants of exits at the national level (Hoppe and Korb 2005). ${ }^{2}$

The annual USDA farmer surveys and the Censuses of Agriculture were not designed to be panel data sets. However, in this chapter we use the Longitudinal Census of Agriculture file that was constructed over time by linking individual farm record data for the five censuses between 1978 and 1997 to document the extent of exit, entry, and growth in U.S. agriculture. Our analysis parallels a number of studies of firm or plant turnover for manufacturing industries in the United States (e.g., Dunne, Roberts, and Samuelson 1988). These studies of various nonagricultural U.S. industries are based on panel data built from economic censuses.

In section 10.2, we describe the way in which the agricultural industry is defined and important characteristics of the industry that have implications for the framework to evaluate the dynamics of the industry. In section

2. Panel data for farms have been available in Canada and Israel for some time and determinants of turnover have been compared for those two countries (Kimhi and Bollman 1999). We would expect the results for Canada to most closely resemble the results for the United States. They found that a major factor explaining exits in Canada was farm size; the larger the farm the less likely to exit. Other determinants of exit were off-farm work (negatively related) and age of the operator. 
10.3 we consider how well the general theoretical frameworks for considering industry dynamics apply to the agricultural industry. Section 10.4 provides a description of the longitudinal data file for agriculture and considers measurement of farm size. Section 10.5 of the chapter presents the empirical analysis of the longitudinal data, summarizing the findings regarding farm entry, exit, and reallocation over the period among surviving farms. We use the term turnover to capture trends on entry and exit of farms (and their inputs and outputs) and the term mobility to capture the trends in the reallocation of inputs and outputs of surviving farms. Finally, the chapter ends with conclusions and suggestions for future work.

\subsection{Defining the Agricultural Industry}

In the United States, a farm is defined (in the Agricultural Census) as any place from which $\$ 1,000$ or more of agricultural product was produced and sold, or normally would have been sold, during the year (USDA 2004a). Hence, it is a very liberal definition and one that assures a very diverse group of establishments will be counted in the farm population. It includes farms operated by households that are retired or attracted to farming for reasons not primarily related to production, such as the rural lifestyle or investment opportunities. In addition, since the definition is dollar-based, it is affected as price levels change. Although changing the definition is regularly discussed, a liberal definition of a farm is very popular with many for a variety of reasons. For example, some Federal program dollars are distributed to states in part based on the farm population in a state (e.g., agricultural extension funds).

The farm sector is a unique sector of the economy in a number of ways. The uniqueness can affect the dynamics of exit, entry, and reallocation of the farm production industry, relative to other industries in the U.S. economy. First of all, most farms are closely-held businesses that combine the production and household choices in one decision-making unit. This requires that economic analyses take into consideration the utility of the household members over the life cycle, as well as profit-maximizing motivations. Secondly, a major input of farms - farmland - is considered fixed and immobile. This has technological, policy, and social implications. For example, the benefits of cost-reducing technologies and the massive government subsidies to the industry generally accrue to the owner of the farmland, who is not always the farm operator. The fixed supply of arable farmland is a focus of those concerned with long-term sustainability as well. Moreover, it could be argued that the family labor is also considered as immobile. A third unique feature of agriculture is its high total factor productivity (TFP) growth relative to most other sectors of the U.S. economy, in large part because of the public investments in Research and Development (Ahearn et al. 1998; Fuglie et al. 1996). While aggregate pro- 
ductivity growth is high, there is a great deal of heterogeneity in productivity across farms. Not unrelated to this heterogeneity is the primary importance of the farm as a residence to the majority of producers. Fourthly, agricultural commodity markets are generally characterized by instability, largely as a result of weather and low price elasticity of demand for food. And, finally, there is an unusually high level of interest in preserving the farming way of life, even by the general population. Public opinion polls have consistently revealed that the U.S. public has an interest in protecting the family farm from the vagaries of the marketplace, and this support has often translated into the transfer of subsidies to the agricultural sector and special treatment in the tax code. Some of the support is likely difficult to separate from the public's support of the environment and scenic vistas since approximately half of the 2 billion acres of U.S. land is in some type of agricultural use.

Federal agricultural-specific policies have long been concerned with the restructuring and reallocation of outputs and inputs across agricultural producers. Current farm policies have their roots in a time around the Great Depression, when farm households were significantly worse off than most households. This condition and its cause in low farm prices due to surpluses of commodities are commonly referred to as the farm problem (Gardner 1992). A reason behind commodity surpluses is technological advances. The standard undergraduate agricultural economics models for understanding the relationship between innovation, surpluses, and reallocation of outputs and inputs are the treadmill and the farmer cannibalism models described by Cochrane (1958). Evidently, Cochrane was greatly influenced by Schumpeter's Theory of Economic Development (1934). The dynamic nature of Schumpeter's process of creative destruction, in particular, was key in Cochrane's development of his models of innovation and reallocation for the farm industry (Levins 2003, p. 28).

\subsection{Relevance of Theoretical Frameworks for Agriculture}

Schumpeter's early work concerning the role of reallocation, in combination with an emerging literature that seeks to account for the heterogeneous performance across firms, forms the theoretical underpinnings of the current empirical work using micro-level firm data. The emerging theoretical models of industry dynamics are carefully reviewed in a number of sources, including Caves (1998). In his review article, Caves links the traditional industrial organization framework with new findings on exit, entry, and mobility of individual firms.

The emerging theoretical models include Jovanovic (1982), Lambson (1991), Hopenhayn (1992), and Ericson and Pakes (1995). What the models have in common is that they assume firms have heterogeneous productive efficiency and are subject to various sources of uncertainty. These assump- 
tions allow the models to explain the divergent paths of entry, exit, and reallocation that characterize the observed firm-level data. These common assumptions of the industry dynamics literature are very consistent with key characteristics of farm firms, as described previously. Namely, micro-level analysis of farms shows extensive cross-sectional productivity and cost differences (e.g., USDA 2004c) and farms are subject to numerous shocks, in particular the classic weather shocks. Numerous applications have considered the role of productivity in the dynamics of nonagricultural industries. Foster, Haltiwanger, and Krizan (2001) provide a recent review of the microeconomic evidence on productivity dynamics.

What the emerging theoretical models do not adequately capture for farming is the role played by the most unique characteristic of farm firms, namely, the dual residence and business objectives of the majority of farm households. As mentioned, the majority of farms are small farms that usually lose money farming when returns only consider before-tax cash costs and returns. Many of these farm households likely receive a variety of returns from farming that are not captured in their before-tax cash income. For example, farm households may simply enjoy farming as a lifestyle and in general these households would have a shadow value of family labor that is less than their opportunity cost. Farm work may even be considered as a leisure activity by these households. The single most powerful trend in resource allocations of farm households during the past several decades is the allocation of household time to the off-farm labor market. More than 70 percent of U.S. farm households have someone in the household working off the farm. This high rate of off-farm labor participation is true, even in very rural areas of the United States.

The unique relationship that a farm household has with the farm business means that micro decisions of farm businesses must be modeled along with micro decisions of farm households in a household production model. Farm households provide most of the labor on the farm and have a tripartite choice of time allocation (farm, off-farm, and leisure hours). The household production model is an extension of the basic labor-leisure model (e.g., Becker 1965). The conceptual model combines the decisions of agricultural households relating to production, consumption, and labor supply into a theoretically consistent model (e.g., Strauss 1986). The individual is assumed to allocate time to farm work, off-farm work, and leisure in such a fashion that the optimal allocation is achieved when the marginal values of time devoted to the activities are equal. Because of the dependence of farm households on off-farm income sources and the fixed supply of household labor, an important component of this literature is the empirical literature on estimating off-farm labor participation and supply (e.g., El-Osta and Ahearn 1996; Hallberg, Findeis, and Lass 1991; Mishra and Goodwin 1997).

The household production model provides demands for farm household 
labor in farming, for leisure time (including personal maintenance time), and off-farm work. One of the possible solutions for the farm household is to provide no labor to the farm business; that is, to exit agriculture entirely. Recent work links agricultural productivity and state-level exit rates in explaining how various Federal policies have affected structure, including participation in off-farm work, over a recent period in the agricultural industry (Ahearn, Yee, and Korb 2005).

\subsection{Measurement Issues: Data Source and Farm Size}

\subsubsection{The Longitudinal File}

The Census of Agriculture has been conducted for over 150 years. In 1997, responsibility was transferred from the Bureau of the Census to National Agricultural Statistics Service, USDA. The Census of Agriculture Longitudinal file is currently a subset of the Census files, developed by combining individual farm operator records for five censuses (1978, 1982, 1987, 1992, and 1997) into one continuous record. Each record represents one individual farm operator's responses about a farm operation to all and/or any censuses. Thus, farms can be followed for a twenty-year period. The file contains 4.5 million observations (records) and eighty-five analysis variables, such as the farm size, economic details about commodities produced, government program participation, county location of the farm, and demographic characteristics of the farm operator. ${ }^{3}$ One obvious weakness of the data for examining turnover and mobility is that the censuses are taken every five years (or four years for the 1978 to 1982 subperiod). Hence, yearto-year changes are likely underestimated.

The longitudinal file attempts to follow farm operations that are tied to the farm land rather than follow individual farm operators. This is done using the Census File Number (CFN). The CFN identifies a farm operation for a particular census, and may follow a farm operation through subsequent censuses (up to five on the longitudinal file). If the farm continues from one census to the next, and the farm operator responds to the census using the same CFN, the information reported by that farm for that census period is appended to the longitudinal file using the same CFN. If the operation changes hands, either through sale or inheritance, the CFN may continue, it may change, or it may be terminated. For example, if an operator dies and leaves a farm to a surviving family member who continues to farm it, then a CFN should continue. However, if a surviving family mem-

3. Analysts can also add any additional variables that are collected on the censuses. The survey instruments are available at the back of each printed census volume and at the NASS website, www.nass.usda.gov 
ber merges the inherited farm with another existing operation with that operation's CFN, then the CFN may change. Farms that are split up may have a portion of their operation continue under the old number and the rest under new number(s), or all parcels of the operation may receive new numbers. In the case where a farm is sold for nonagricultural purposes, then the CFN is terminated. A farm is defined as going out of business when either the questionnaire is returned with the indication that it is no longer operating as a farm, or there is no response to repeated requests for information. The absence of a farm in a particular census year is represented in the longitudinal file by zeros for all the variables for that observation for that year. We consider a farm to be out of business (an exit) when zeroes in the $\mathrm{CFN}$ field indicate that the farm has been discontinued. When a particular CFN is classified as an exit through the process described previously, it is not possible to determine if the exit was the result of a merger with another farm or the result of the exiting farm being used for a nonfarm purpose. Likewise, a farm operation with a CFN that is not matched or linked to a previous longitudinal record would be considered a new business and added to the longitudinal file as a new record. This is an entry. A farm which has a CFN for both a beginning and an ending census time period in its record is considered to be a survivor. Most observations on the longitudinal file represent only themselves and are assigned a nonresponse weight of one. Some farms have a weight greater than one, meaning they represent themselves and other farms (or portions of farms) that did not respond to the Census.

\subsubsection{Farm Size: Measurement and Aggregate Distribution}

There are a variety of ways in which farm size is measured, and the topic is occasionally reevaluated in agricultural economics (e.g., see Hanson, Stanton, and Ahearn 1989; Sumner and Wolf 2002; Yee and Ahearn 2005). Two of the most common ways to measure farm size in statistical publications are in terms of farm acres (an input measure) and the dollar value of gross sales (an output measure). The advantage of the acre-based measure is that land is generally viewed as a key production input in farming and an acre is a clearly defined unit of measurement. It can be considered as the counterpart to a measure of employment in manufacturing or service industries. The relative proportion of land as a production input varies considerably by technology, and the quality of an acre of land varies considerably over space. Output-based measures, such as the gross sales measure, avoid the major disadvantages of the acre-based measure. However, outputbased measures can interject biases as a result of the differences across commodities in farm value-added and in the changing value of the dollar over time, not to mention transitory output variations (Stanton et al. 1992). In this chapter, we focus largely on the acreage-based size. 
As mentioned, the average farm acreage has been quite stable in recent decades. The average acreage was 449 in 1978, compared to 441 in $2002 .{ }^{4}$ Average farm acreage is significantly greater in western states than in the East, but farm sizes are highly dispersed in all regions. This is in part because of the shape of the cost curve. It is generally thought to be L-shaped, with the low-cost plateau occurring at a relatively small farm size. Again, the role of technology is important here because there are differing lowcost technologies available for farms of different sizes. The prevalence of off-farm income is another reason we observe a significant share of small farms. While small farms may be efficient from a technical viewpoint, they nevertheless usually do not generate enough cash income to support a family. Off-farm work opportunities allow many farm families to be engaged in farming and its lifestyle amenities.

Both the small farms and the very largest farms are increasing as a share of the total farms during the period 1978 to 1997. The size distribution of farms is heavily skewed toward the small farms, while the production in agriculture is largely concentrated on the large farms. Approximately 2.4 percent of the largest farms (or 46,000 farms) accounted for half of all product in 1997. ${ }^{5}$ The increased concentration in production is only expected to continue in the future. However, it is still clear that with its more than 2 million farms, agriculture is not in danger of losing its poster child status for an industry characterized by many producer/sellers.

\subsection{Empirical Evidence, 1978 to 1997}

As mentioned, the traditional indicators of farm structure are widely available and document the extensive heterogeneity in farm structure. We focus our description of farm structure on the largely unavailable statistics of dynamic change for the 1978 to 1997 time period. ${ }^{6}$ We first consider turnover - exit, entry, and volatility - for all farms and by farm size. We next consider the mobility of surviving farms.

\subsubsection{Turnover}

Exit, entrant, and surviving farm rates vary by inter-census time period (fig. 10.1). Many farms go out of business and many new farms come into business. In the 1978 to 1982 period and the 1992 to 1997 period, the number of farms that entered the farm sector exceeded the number of farms

4. The original 1997 census estimate was 487 acres per farm, and the revised estimate is 431 acres per farm.

5. By the year 2002, there were 34,000 (or 1.6 percent of farms) that accounted for half of the product.

6. The 2002 Census of Agriculture has not yet been added to the longitudinal database. With the release of the 2002 Census the number of farms in 1997 has been revised upward due to an adjustment in weights based on a survey of undercoverage. However, the revision to the 1997 Census will not be incorporated into the longitudinal file. 


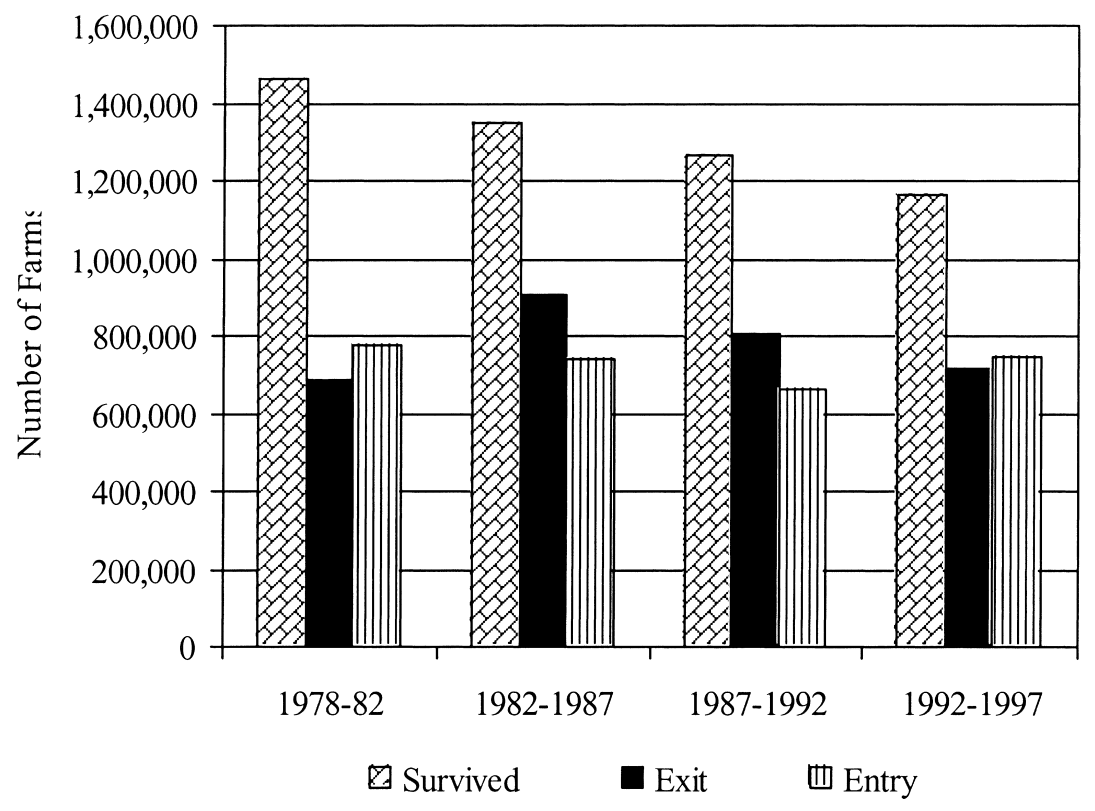

Fig. 10.1 U.S. Farm dynamics, 1978-1997

Source: Compiled by the Economic Research Service from Census of Agriculture data.

that exited. In the two intervening census periods, the opposite was true. For example, in 199762 percent of the farms that existed in 1992 were still in existence, and 38 percent of the 1992 farms had exited. However, slightly more farms entered farming during the period as exited. Contrast those significant changes to the slight increase in the net number of total farms between the 1992 Census of Agriculture and the 1997 Census. When annualized, the entry and exit rates are somewhat greater than those reported by Dunne, Roberts, and Samuelson (1988) for U.S. manufacturing industries in an earlier period. They report a 7.7 percent annual entry rate and a very similar 7.0 percent annual exit rate for the 1963 to 1982 period for manufacturing in general, but they also report significant variation across manufacturing industries.

Another statistic used to characterize the turnover in an industry is the volatility of the industry. Volatility is defined as the sum of the entry and exit rate minus the absolute value of the net entry rate. It can be interpreted as a measure of the amount of producer turnover that is in excess of the amount needed to account for the change in industry size (Dunne and Roberts 1991). Given both the high rates of entry and exits, the volatility rate in farming is about double the entry and exit rates. The positive correlation between entry and exit rates is consistent with the findings reported for other industries (Caves 1998). 
Turnover statistics are sometimes calculated for output or employment. For farming, it makes sense to calculate entry, exit, and volatility rates for output (value of sales) and acres of farmland. ${ }^{7}$ The total land in agriculture is relatively stable over time, but there is also some shifting of land. Land moves to and from agricultural and nonagricultural uses, for example, between agricultural and forest uses. Land also shifts among agricultural uses, such as pasture and cropland. Much of the land operated by the farms that exit agriculture is subsequently purchased or rented by existing farms to expand their operation. In general, entry, exit, and volatility rates were lower for acres than they were for farm firms during these periods. Entry rates for farmland acres exceeded the exit rates in the first two subperiods and the opposite was true for the last two Census subperiods. Only in two Census subperiods was there a positive relationship between turnover in farm firms and turnover in farmland (table 10.1). Entry rates for value of sales were similar to those rates for acres of farmland, but exit rates, and hence, volatility rates, were lower for value of sales than they were for acres of farmland. This indicates that those acres that went out of production contributed less to value of sales per acre than the acres that continued in production. At the end of each of the four subperiods considered, farms that had entered during the period accounted for 28 to 32 percent of all sales of the farming sector.

Turnover as exhibited by these data has been largely uncorrelated with market conditions. For example, the early 1980s were known as a difficult financial time for some farms, especially those specializing in rice, cotton, and certain cash grains, such as corn and soybeans. Although we did not find strong evidence of Shumpeter's creative destruction at work when we look at all farms combined, when we examine turnover by the type of commodity in which farms specialize we find some evidence that market conditions do play a role. During the 1982 to 1987 Census subperiod, more farms exited than entered for some cash grain, cotton, and rice producers. In addition, during this period, the average sales of the exitors exceeded the average sales of the continuing farms in these specialties.

\subsubsection{Turnover by Farm Size}

In general, the average farm size in acres was larger for surviving farms than it was for either exiting or entering farms during the four subperiods (table 10.2). Also, the average size of surviving farms increased over the full 1978 to 1997 period by thirty-three acres, from 495 acres to 528 acres, although there was no change in the average size of farms during the last two subperiods. Exiting farms were larger in the initial subperiod and in the

7. This is not unlike the tracking of jobs in manufacturing industries; tracking of jobs in agriculture is problematic since much of the labor is unpaid and many workers are multiplejob holders. 
Table 10.1

Entry, exit, and volatility rates for farms, acres of farmland, and value of sales, for Census subperiods

\begin{tabular}{|c|c|c|c|c|c|c|}
\hline & \multicolumn{2}{|c|}{ Entry rate $(\%)$} & \multicolumn{2}{|c|}{ Exit rate $(\%)$} & \multicolumn{2}{|c|}{ Volatility (\%) } \\
\hline & Subperiod & Annual & Subperiod & Annual & Subperiod & Annual \\
\hline \multicolumn{7}{|l|}{ Farms } \\
\hline 1978-1982 & 37 & 11 & 33 & 10 & 66 & 20 \\
\hline 1982-1987 & 33 & 9 & 40 & 10 & 66 & 18 \\
\hline 1987-1992 & 32 & 8 & 38 & 10 & 63 & 17 \\
\hline 1992-1997 & 39 & 10 & 37 & 9 & 74 & 19 \\
\hline \multicolumn{7}{|l|}{ Acres } \\
\hline $1978-1982$ & 28 & 8 & 26 & 8 & 53 & 15 \\
\hline 1982-1987 & 34 & 8 & 30 & 7 & 61 & 14 \\
\hline 1987-1992 & 26 & 6 & 30 & 7 & 51 & 12 \\
\hline 1992-1997 & 30 & 7 & 32 & 8 & 60 & 15 \\
\hline \multicolumn{7}{|l|}{ Value of sales } \\
\hline 1978-1982 & 31 & 8 & 20 & 5 & 39 & 11 \\
\hline $1982-1987$ & 32 & 8 & 33 & 8 & 63 & 15 \\
\hline 1987-1992 & 29 & 6 & 24 & 5 & 47 & 11 \\
\hline 1992-1997 & 35 & 8 & 24 & 6 & 49 & 11 \\
\hline
\end{tabular}

Table 10.2

Average farm size in acres of entering, exiting, and surviving farms, 1978-1997

\begin{tabular}{cccc}
\hline & Entrants & Exits & Surviving \\
\hline $1978-1982$ & 344 & 359 & 495 \\
$1982-1987$ & 391 & 355 & 498 \\
$1987-1992$ & 373 & 357 & 528 \\
$1992-1997$ & 380 & 428 & 528 \\
\hline
\end{tabular}

1992 to 1997 subperiod than were the entering farms. Recall that it was in these two subperiods where entry rates slightly exceeded exit rates. That is, during the periods when more farms were entering farming than leaving farming, the average size of the entering farms was less than the average size of exiting farms. In the 1992 to 1997 period, the entry rate of farms exceeded the exit rate, but more total acres left agriculture than entered agricultural uses because the average farm that exited the sector was larger than the average entering farm, while at the same time the average size of the continuing farm remained constant from the previous period.

Unlike the textbook explanation that holds that new firms enter at the optimal size, we find farms entering at all sizes. However, exit rates, entry rates, and survival rates vary considerably by size of farm. We have calculated entry and exit rates for farms and farmland for various size classes for the four subperiods (tables 10.3 and 10.4). Exit and entry rates are higher 
Table 10.3

\begin{tabular}{lcccc}
\hline Acre class & $1978-1982$ & $1982-1987$ & $1987-1992$ & $1992-1997$ \\
\hline & \multicolumn{4}{c}{ Exit rate for farms $(\%)$} \\
$1-49$ & 42 & 51 & 49 & 47 \\
$50-99$ & 35 & 41 & 40 & 38 \\
$100-179$ & 32 & 38 & 37 & 36 \\
$180-259$ & 29 & 35 & 34 & 33 \\
$260-499$ & 27 & 34 & 32 & 31 \\
$500-999$ & 26 & 33 & 30 & 30 \\
$1,000-1,999$ & 26 & 31 & 27 & 28 \\
2,000 plus & 26 & 31 & 27 & 30 \\
& & & & \\
$1-49$ & 38 & 47 & 45 & 43 \\
$50-99$ & 35 & 38 & 40 & 38 \\
$100-179$ & 32 & 35 & 37 & 35 \\
$180-259$ & 29 & 34 & 32 & 33 \\
$260-499$ & 27 & 32 & 30 & 29 \\
$500-999$ & 26 & 31 & 27 & 28 \\
$1,000-1,999$ & 26 & 31 & 28 & 34 \\
2,000 plus & 25 & & & \\
\hline
\end{tabular}

Table 10.4

\begin{tabular}{lcccc}
\hline Acre class & $1978-1982$ & $1982-1987$ & $1987-1992$ & $1992-1997$ \\
\hline \multicolumn{4}{c}{ Entry rate for farms (\%) } \\
$1-49$ & 51 & 48 & 46 & 49 \\
$50-99$ & 35 & 34 & 34 & 41 \\
$100-179$ & 31 & 32 & 31 & 36 \\
$180-259$ & 28 & 29 & 28 & 32 \\
$260-499$ & 27 & 28 & 27 & 29 \\
$500-999$ & 27 & 29 & 25 & 27 \\
$1,000-1,999$ & 27 & 30 & 25 & 27 \\
2,000 plus & 28 & 31 & 27 & 29 \\
& & & & \\
$1-49$ & 45 & 32 & 42 & 47 \\
$50-99$ & 35 & 31 & 34 & 41 \\
$100-179$ & 31 & 29 & 31 & 36 \\
$180-259$ & 28 & 28 & 28 & 32 \\
$260-499$ & 26 & 29 & 26 & 29 \\
$500-999$ & 27 & 30 & 25 & 27 \\
$1,000-1,999$ & 27 & 31 & 25 & 27 \\
2,000 plus & 28 & & 26 & 32 \\
\hline
\end{tabular}

Entry rates by farm size (measured in acres) for farm firms and farmland 
for small farms and decline steadily until farms reach a midsize range of 260 acres or more. The exit and entry rates flatten out considerably for the large size classes. In general, there are not large gaps between exit and entry rates over time. However, at the beginning of the period, entry rates slightly exceeded exit rates for large farms and the very smallest farms. (This was true for acres of land operated by those sizes of farms, too.) The early 1980s was the beginning of a time of significant financial stress for U.S. agriculture and the beginning of the consequent adjustment. There had been significant expansion in U.S. production prior to that period as international markets for U.S. products grew at a rapid rate, and then for a variety of reasons (including the contraction of the international demand for U.S. products) the United States had significant surpluses of agricultural commodities. The consequent adjustments are clear in the entry and exit rates. In the latter part of the period, 1992 to 1997, entry rates exceeded exit rates for the small farms. This reflects the growing demand for farms as high-quality rural residences, which continues today.

It is also useful to consider relationships by farm size when size is measured by gross sales. The general trends in exit and entry rates by the gross sales size measure are similar to the acre size measure. By a gross sales measure, very small farms (with gross sales of less than $\$ 10,000$ ) have the lowest survival rates. Survival rates are also low for the next size of farms ( $\$ 10,000$ to $\$ 99,999$ in gross sales), but somewhat higher than for the smallest farms. These two smallest categories of farms represent about 85 percent of all U.S. farms, but only 10 percent of farm output. Prior to 1987, the survival rates of the midsized farms $(\$ 100,000$ to $\$ 249,999)$ were on par with the largest farms in the sector, but since that time have been somewhat below the survival rates of the larger farms.

Across the United States, since small farms are more likely to exit farming than large farms, we see the highest exit rates in those states that have large proportions of small farms. Small farms often require off-farm employment opportunities for their survival, and these are more likely to be available in or near metropolitan areas. The South and the East have the highest share of operators working off their farm full-time (200 or more days per year). In contrast, large farms require high quality agricultural resources - land and climate-and for some commodities, are recipients of government support. Farms in metropolitan areas are more likely to change ownership than farms in more rural areas for a variety of reasons, including the higher probability that farming is a secondary occupation of the operator and that the land is in higher demand for urban conversion.

\subsubsection{Mobility of Surviving Farms}

We consider several aspects of the mobility of surviving farms in the results presented in tables 10.5 through 10.7. In table 10.5, we examine the survival rates, market shares (in sales and acres), and average farm size (in sales 
Table 10.5

Survival rates, market shares, and average farm sizes of entry cohorts

by year

\begin{tabular}{|c|c|c|c|c|c|}
\hline & 1978 & 1982 & 1987 & 1992 & 1997 \\
\hline \multicolumn{6}{|c|}{ Survival rate (farms) } \\
\hline 1978 farms & 1.000 & 0.703 & 0.482 & 0.331 & 0.228 \\
\hline 1982 entry cohort & & 1.000 & 0.446 & 0.279 & 0.189 \\
\hline 1987 entry cohort & & & 1.000 & 0.486 & 0.307 \\
\hline 1992 entry cohort & & & & 1.000 & 0.482 \\
\hline 1997 entry cohort & & & & & 1.000 \\
\hline \multicolumn{6}{|c|}{ Market share (sales) } \\
\hline 1978 farms & 1.000 & 0.725 & 0.508 & 0.377 & 0.265 \\
\hline 1982 entry cohort & & 0.275 & 0.169 & 0.129 & 0.097 \\
\hline 1987 entry cohort & & & 0.323 & 0.212 & 0.152 \\
\hline 1992 entry cohort & & & & 0.282 & 0.183 \\
\hline 1997 entry cohort & & & & & 0.303 \\
\hline \multicolumn{6}{|c|}{ Market share (acres) } \\
\hline 1978 farms & 1.000 & 0.730 & 0.543 & 0.427 & 0.312 \\
\hline 1982 entry cohort & & 0.270 & 0.157 & 0.118 & 0.090 \\
\hline 1987 entry cohort & & & 0.299 & 0.193 & 0.135 \\
\hline 1992 entry cohort & & & & 0.261 & 0.159 \\
\hline 1997 entry cohort & & & & & 0.304 \\
\hline \multicolumn{6}{|c|}{ Average size of surviving farms relative to all farms (sales) } \\
\hline 1978 farms & 1.000 & 1.110 & 1.058 & 1.055 & 1.069 \\
\hline 1982 entry cohort & & 0.793 & 1.020 & 1.147 & 1.260 \\
\hline 1987 entry cohort & & & 0.912 & 1.139 & 1.280 \\
\hline 1992 entry cohort & & & & 0.820 & 1.098 \\
\hline 1997 entry cohort & & & & & 0.778 \\
\hline \multicolumn{6}{|c|}{ Average size of surviving farms relative to all farms (acres) } \\
\hline 1978 farms & 1.000 & 1.117 & 1.131 & 1.194 & 1.258 \\
\hline 1982 entry cohort & & 0.780 & 0.948 & 1.053 & 1.170 \\
\hline 1987 entry cohort & & & 0.846 & 1.038 & 1.142 \\
\hline 1992 entry cohort & & & & 0.760 & 0.950 \\
\hline 1997 entry cohort & & & & & 0.780 \\
\hline
\end{tabular}

and acres) of entry cohorts over time. The 1978 base period will include all farms. (This explains why the proportion is 1.0 in the 1978 column.) The cell that corresponds to the 1982 column of data and the 1978 farms row is for all farms that existed in 1978, regardless of when they entered, and survived through 1982. Hence, the 1978 row is not exactly comparable to the other rows where we can identify the entry cohort year. Notice that the 1-period survival rate for the 1978 farms was much higher (0.703) than the 1-period survival rate for the subsequent entry cohorts (i.e., $0.446,0.486,0.482$ ). New entrants have lower survival rates than farms with more experience. The twenty-year survival rate for farms that existed in 1978 was about 23 percent. Also, the farms that existed in 1978 and survived over the periods were 
all larger than the industry average at each period. In spite of their greater size, their market shares declined as a group because many of the farms that existed in 1978 exited the sector over time.

The 1982 to 1997 entry cohorts had market shares from 28 to 32 percent, and controlled a comparable 26 to 30 percent of farmland. The bottom two sections of table 10.5 indicate the size of entry cohorts (in sales and acres) relative to all farms at the time period. In the initial census entry year, the entry cohort is smaller than all farms in the sector. However, by the next census period, these newest entry cohorts in the agricultural industry are at least 95 percent as large as all farms, but usually larger. For example, the entering farms in 1982 were 79 percent the size of the average farm. However, by 1997, the size of the surviving members of the 1982 cohort were 126 percent the size of the average farm. The average size of surviving farms can increase as the cohort ages because the smaller farms exit and/or the surviving farms increase in size. Supporting evidence suggest that both phenomena take place. It is also worth noting that the 1987 entry cohort stands out among the entry cohorts as being somewhat larger and capturing a higher market share than other years. This finding is consistent with the results we reported above on entry and exit rates by farm size for the 1982 to 1987 period.

The results in table 10.5 are similar to those of Dunne, Roberts, and Samuelson (1988) who use Census of Manufactures data for 387 manufacturing industries for the 1963 to 1982 period. They also found that, on average, there is a decline in the market share of each entering cohort as it ages. This reflects a decline in the number of firms in the cohort that more than offsets the rise in the average size of the surviving members of the cohort relative to all firms in the industry. Survival rates are lower in manufacturing than in agriculture. This could be true for a number of reasons described earlier (e.g., favorable government policies and the strong household link to the business). Dunne, Roberts, and Samuelson also reported lower market shares of entrants than we found for agriculture, perhaps because of the large share of farms that serve more as rural residences for the farm family than as money-making business ventures.

Mobility of continuing farms in the shares of output (or acres of farmland) is usually measured by summing the absolute values of the differences between their output (acres) at $t$ and $t+1$ and dividing by the sum of their output (acres) at $t$. Table 10.6 provides this measure of mobility for the four Census subperiods for both output and acres of farmland. When we consider all surviving farms, the mobility in output varies from a high of 72 percent in the first subperiod to a low of 51 percent in the 1982 to 1987 subperiod. The 1982 to 1987 period again stands out among the four subperiods. It had the smallest sum of (absolute value in) differences in output from the beginning to the end of the period and had the smallest share of farms that increased their sales during the period-less than half 
Table 10.6

Mobility indicators for output and acres of farmland for surviving farms, by Census subperiod

\begin{tabular}{lccc}
\hline All surviving farms & Value of product $^{\mathrm{a}}(\%)$ & Acres $(\%)$ & Farms $(\%)$ \\
\hline $1978-1982$ & 72 & 26 & 100 \\
$1982-1987$ & 51 & 31 & 100 \\
$1987-1992$ & 68 & 35 & 100 \\
$1992-1997$ & 68 & 37 & 100 \\
& Value of product increased $^{b}$ & & \\
$1978-1982$ & 87 & 26 & 67 \\
$1982-1987$ & 68 & 36 & 47 \\
$1987-1992$ & 84 & 36 & 63 \\
$1992-1997$ & 86 & 39 & 59 \\
& Value of product decreased $^{b}$ & & \\
$1978-1982$ & 41 & 29 & 33 \\
$1982-1987$ & 41 & 28 & 53 \\
$1987-1992$ & 43 & 34 & 37 \\
$1992-1997$ & 43 & 36 & 41 \\
\hline
\end{tabular}

${ }^{a}$ Value of product is the total value of sales and the value of product removed under contract in 1997 dollars.

${ }^{b}$ Excludes less than 1 percent of farms that had no value of sales in either period.

of continuing farms increased their output during this period. This is a reflection of the financial stress in agriculture during that particular period. The mobility in acres is much less than for output for each subperiod, but shows a consistent increase over the subperiods. In agriculture, we expect more variation in output over time, given the vagaries of weather and market prices, in contrast to the input of farmland.

Baldwin (1995) highlighted the differences in mobility in employment by dividing Canadian manufacturing firms into those that gained and those that lost employment. In a similar fashion, we divided farms into those that had increasing value of product and those that had decreasing value of product over the subperiods, and then examined their mobility in output and acres of farmland. Farms that increased their output had significantly greater mobility than those that decreased their output. Again, for acres we see lower mobility and no difference by whether or not sales increased or decreased over the subperiods.

In table 10.7, we consider how surviving farms change size over time. We calculated detailed transition matrices for each of the four census subperiods by size of farm, where size is measured in acres. We present the share of those remaining in the size class at the end of the period as a share of those that started in the size class at the beginning of the period, averaged over the four time periods. (The shares do not sum to 1.0 because exits and entrants are excluded.) The majority of surviving farms stay in the same size class (i.e., are along the diagonal of the tables). The smallest farms (1 
Transition matrix for surviving farms and acres, by acreage size class

(four-period average)

\begin{tabular}{lcccccccc}
\hline & \multicolumn{7}{c}{ Ending acre class } \\
\cline { 2 - 9 } $\begin{array}{l}\text { Beginning } \\
\text { acre class }\end{array}$ & $1-49$ & $50-99$ & $100-179$ & $180-259$ & $260-499$ & $500-999$ & $1,000-1,999$ & $2,000+$ \\
\hline & & \multicolumn{7}{c}{ Number of farms } \\
$1-49$ & 0.429 & 0.050 & 0.025 & 0.009 & 0.009 & 0.004 & 0.001 & 0.001 \\
$50-99$ & 0.087 & 0.407 & 0.077 & 0.021 & 0.016 & 0.005 & 0.001 & 0.001 \\
$100-179$ & 0.039 & 0.071 & 0.415 & 0.061 & 0.040 & 0.011 & 0.003 & 0.001 \\
$180-259$ & 0.026 & 0.031 & 0.104 & 0.366 & 0.114 & 0.024 & 0.005 & 0.002 \\
$260-499$ & 0.017 & 0.016 & 0.043 & 0.069 & 0.434 & 0.094 & 0.013 & 0.003 \\
$500-999$ & 0.011 & 0.007 & 0.016 & 0.018 & 0.104 & 0.451 & 0.088 & 0.011 \\
$1,000-1,999$ & 0.008 & 0.004 & 0.009 & 0.007 & 0.026 & 0.114 & 0.466 & 0.085 \\
$2,000+$ & 0.007 & 0.002 & 0.005 & 0.004 & 0.011 & 0.024 & 0.086 & 0.576 \\
& & & & & & & & \\
$1-49$ & 0.411 & 0.064 & 0.027 & 0.009 & 0.008 & 0.003 & 0.001 & 0.001 \\
$50-99$ & 0.076 & 0.379 & 0.077 & 0.021 & 0.015 & 0.005 & 0.001 & 0.001 \\
$100-179$ & 0.036 & 0.062 & 0.387 & 0.061 & 0.040 & 0.011 & 0.003 & 0.001 \\
$180-259$ & 0.024 & 0.029 & 0.095 & 0.343 & 0.111 & 0.023 & 0.005 & 0.001 \\
$260-499$ & 0.016 & 0.014 & 0.039 & 0.060 & 0.407 & 0.099 & 0.013 & 0.003 \\
$500-999$ & 0.010 & 0.007 & 0.015 & 0.016 & 0.090 & 0.425 & 0.095 & 0.012 \\
$1,000-1,999$ & 0.007 & 0.004 & 0.008 & 0.007 & 0.024 & 0.099 & 0.441 & 0.093 \\
$2,000+$ & 0.005 & 0.002 & 0.003 & 0.002 & 0.006 & 0.013 & 0.036 & 0.599 \\
\hline
\end{tabular}

to 49 acres) and the larger farms have the highest share of farms remaining in their size class for each subperiod. Not surprisingly, the surviving large farms with an unconstrained size category were most likely to stay in the large category, since they had nowhere to go, except to contract. Midsized farms were the least likely to remain in their size class, and were somewhat more likely to contract in size than to expand. Given the stability in the farms along the diagonal, the size distribution (by these aggregated acreage classes) of all surviving farms has changed little over the subperiods. The stability of the size distribution of firms has been observed for nonagricultural industries as well. The stability in the size distribution of the surviving farms underscores the role played by new entrants and exiting farms in affecting the aggregate size distribution.

The results in table 10.7 indicate when surviving farms changed their size category. However, many farms stay within an arbitrary size category and change their acres operated to a smaller extent. We found that, over any given period, the majority of farms change size. For example, during the 1992 to 1997 period, only about 30 percent of the surviving farms did not expand or reduce their acres operated at all. And small farms are less likely to expand, while large farms are more likely to get larger. This result differs for the result generally found for nonfarm industries, where the average growth rate of continuing firms generally declines with firm size. This 


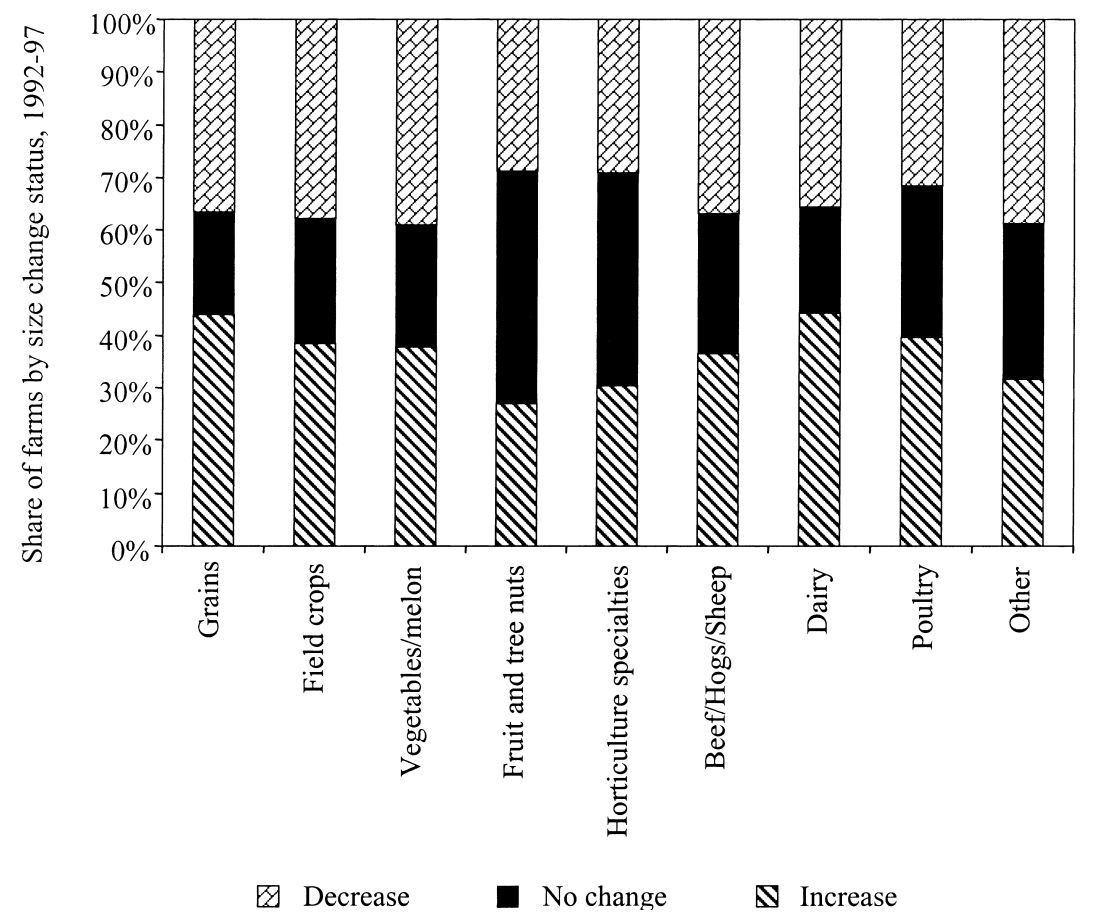

Fig. 10.2 Surviving farm changes in acreage by farm specialization, 1992-1997

Source: Compiled by the Economic Research Service from Census of Agriculture data.

difference for farming is likely the result of the unique dual role played by farms as both business and residence, oftentimes with the residence being the predominant motivation for being in farming.

There is some variation in the tendency of surviving farms to change size based upon the type of commodity in which they specialize. Some commodity specializations require more fixed investment than others; therefore, we would expect those specializations to exhibit more stability in farm size and turnover. This is certainly the case for farms that specialize in fruit and tree nuts and horticulture specialties in 1992 to 1997 (fig. 10.2). One might also expect relative stability in dairy operations, given the large fixed investment of that specialization. However, we see just the opposite. This is likely because of the increased economic pressure to increase dairy farm size. Restructuring of dairy production has been going on for some time, including the movement of production out of the traditional midwestern dairy states towards southern climates. California is now the largest dairy state in the nation. ${ }^{8}$

8. In fact, California is the top producer for one-third of the twenty-five major commodity groups. 
The least developed area of the United States is the mid-region of the country; in contrast, the two coasts are the most developed. While there is significant variation in level of development within a state, the link between level of metropolitan development and farm survivability is even crudely evident at the state level. The lowest survivability of farms is along the two coastlines, which have the most developed land and the greatest proportion of small farms. The more populated areas of the United States have both greater entry and greater exit rates than the less populated areas. The midsection of the country clearly has the greatest farm survivorship. The midsection of the country has some of the highest rates of farm expansion, along with areas of the Southeast and the Southwest. The joint distribution of these two indicators of dynamics shows that in some areas, when farms exit, the farm resources are largely used to expand existing farms. This is the case for the Southeast. In others areas, like the Northeast, when farms exit, entering farmers are operating farms of approximately the same size as those that exiting farmers operated. The strong farm economy of the midsection of the country is evident from both high survivability levels and farm expansion. An important factor in the farm economy in this region is the high level of government farm subsidies. For example, in 2000, government farm payments were nearly $\$ 23$ billion, and seven states in the midsection of the country exceeded $\$ 1$ billion. Those states were Illinois, Indiana, Iowa, Minnesota, Nebraska, North Dakota, and Texas. Combined, they received half of the total subsidies in that year.

\subsection{Summary and Conclusions}

This chapter draws on a unique panel data set, the longitudinal Census of Agriculture data for 1978 to 1997, to examine turnovers and mobility in U.S. agriculture. The data are widely used in their published aggregate form for individual censuses, but only recently used in a panel file. The microanalysis of turnovers shows considerable structural change underlying the traditional aggregate indicators of farm structure. For example, the data show that in 1997, 62 percent of the farms that existed in 1992 were still in existence, and 38 percent of the 1992 farms exited. In contrast, the net change reflected in the aggregate statistics reported a net change of 1 percent.

This analysis for agriculture is in the same vein as work that has occurred for other industries in the United States and elsewhere, often focused on manufacturing. For example, Caves (1998) provides a review of these studies. Many of the stylized facts that have emerged from the literature synthesized by previous studies are relevant to our findings for agriculture.

Our major findings for agriculture are:

- The rate of entry and exit varies somewhat over time, and their generally positive correlation is consistent with the findings reported for 
other industries; however, entry and exit rates in agriculture are somewhat higher than in manufacturing.

- The entry and exit of farms are involved in the growth-farm size relationships. Although farms enter and exit at all farm sizes, entry and exit are more likely to occur among small farms.

- The entry, exit, and volatility rates were lower for farmland acres (a key input in farming) than they were for farm firms.

- Turnover and resource mobility have been largely uncorrelated with market conditions. The exception to this is for certain specializations during the stressful subperiod of 1982 to 1987.

- There is large-scale reallocation of outputs and inputs in agriculture. Entering farms, for example, account for about 30 percent of all output over the time period studied, which is higher than those shares reported elsewhere for manufacturing.

- Approximately 23 percent of the farms that existed in 1978 survived to 1997.

- Surviving farms are larger on average than either exiting or entering farms.

- The mobility of surviving farms in output varies significantly. The 1982 to 1987 subperiod had the lowest mobility and the smallest share of farms that increased their sales during the period - less than half of continuing farms increased their output during this period.

- The majority of surviving farms change their farm size, and in some cases the changes are large enough to put them in a larger acreage class, thereby affecting the aggregate size distribution. Small farms are less likely to expand, while large farms are more likely to get larger. This result differs for the result generally found for nonfarm industries, where the average growth rate of surviving firms generally declines with firm size. The difference for farming is likely the result of the unique dual role played by farms as both business and residence.

There is not a clear view regarding the most dominant factors in the structural change process in agriculture. Our description of farm structural change underlying the traditional aggregate indicators (i.e., the turnover and reallocation indicators) underscores the challenge in drawing simple generalizations about the process. The dearth of empirical applications of models is likely a result of the complexity of factors that are related to structural change and the importance of identifying their separate roles. The structural change process is a macro event that occurs rather slowly over time as a result of micro-level decisions. Hence, it is important to empirically consider both micro-level paths of firms and to measure the body of interactions over time to gain insight into the key determinants of productivity growth and change. Unlike for agriculture, the panel data set in manufacturing allows for an analysis of total factor productivity and the role 
turnover and reallocation of output and inputs plays in the level of an industry's aggregate total factor productivity. Another barrier to total factor productivity measurement with the Census of Agriculture data are the complexities associated with the variation in the natural resource input across farms and the fundamental importance of site-specific commodity mix.

Although agriculture accounts for less than 2 percent of the GDP, the sector has special policy significance. One of those interests is the structure of the farming industry. In order to understand the sources of structural change, the relationships must be considered over time because of the lengthy lags of their impacts, policy and otherwise. In addition, structural change must be considered in the context of the whole farm sector because of the extensive linkages in the marketplace for land, inputs, and outputs, agricultural and otherwise. Our results support the view that the structural change process is a complex one, involving the interplay among technological change, market forces, and public policies. Consequently, policies designed to impact a single target, such as productivity or family farm survivability, will likely have reverberating structural implications, perhaps even counterintuitive or unwanted effects.

\section{References}

Ahearn, M., J. Yee, E. Ball, and R. Nehring. 1998. Agricultural productivity in the United States. Agriculture Information Bulletin No. 740 (January) Washington, D.C.: U.S. Department of Agriculture, Economic Research Service.

Ahearn, M., J. Yee, and P. Korb. 2005. Effects of differing farm policies on farm structure and dynamics. American Journal of Agricultural Economics 87 (5): 1182-89.

Baldwin, J. 1995. The dynamics of industrial competition. Cambridge: Cambridge University Press.

Barkley, A. P. 1990. The determinants of the migration of labor out of agriculture in the United States, 1940-85. American Journal of Agricultural Economics 72 (3): 567-73.

Becker, G. S. 1965. A theory of the allocation of time. Economic Journal 75 (299): 493-517.

Bentley, S. E., P. F. Bartlett, F. L. Leistritz, S. H. Murdock, W. E. Saupe, D. E. Albrecht, B. L. Ekstrom, et al. 1989. Involuntary exits from farming: evidence from four studies. Agriculture Economic Report No. 625 (November). Washington, D.C.: U.S. Department of Agriculture, Economic Research Service.

Bentley, S. E., and W. Saupe. 1990. Exits from farming in southwestern Wisconsin, 1982-1986. Agriculture Economic Report No. 631 (February). Washington, D.C.: U.S. Department of Agriculture, Economic Research Service.

Caves, R. E. 1998. Industrial organization and new findings on the turnover and mobility of firms. Journal of Economic Literature 36 (4): 1947-82.

Cochrane, W. 1958. Farm prices: Myth and reality. Minneapolis, MN: University of Minnesota Press. 
Dunne, T., and M. Roberts. 1991. Variation in producer turnover across U.S. manufacturing industries. In Entry and market contestability, ed. P. A. Geroski and J. Schwalbach, 187-203. Oxford, U.K.: Basil Blackwell Ltd.

Dunne, T., M. Roberts, and L. Samuelson. 1988. Patterns of firm entry and exit in U.S. manufacturing industries. RAND Journal of Economics 19 (4): 495-515.

Edwards, C., M. G. Smith, and R. N. Peterson. 1985. The changing distribution of farms by size: A markov analysis. Agricultural Economics Research 37 (4): 1-16.

El-Osta, H., and M. Ahearn. 1996. Estimating the opportunity cost of unpaid farm labor for U.S. farm operators. U.S. Department of Agriculture, Economic Research Service Technical Bulletin No. 1848, March.

Ericson, R., and A. Pakes. 1995. Markov-Perfect industry dynamics: A framework for empirical work. Review of Economic Studies 62 (1): 53-82.

Foltz, J. 2004. Entry, exit, and farm size: Assessing an experiment in dairy price policy. American Journal of Agricultural Economics 86 (3): 594-604.

Foster, L., J. Haltiwanger, and C. J. Krizan. 2001. 2000. Aggregate productivity growth: Lessons from microeconomics evidence. In New developments in productivity analysis, ed. C. R. Hulten, E. R. Dean, and M. J. Harper, 303-63. Chicago: The University of Chicago Press.

Fuglie, K., N. Ballenger, K. Day, C. Klotz, M. Ollinger, J. Reilly, U. Vasavada, and J. Yee. 1996. Agricultural research and development: Public and private investments under alternative markets and institutions. Agricultural Economics Report 735. U.S. Department of Agriculture, Economic Research Service.

Gardner, B. L. 1992. Changing economic perspectives on the farm problem. Journal of Economic Literature 30 (1): 62-101.

Goetz, S., and D. Debertin. 2001. Why farmers quit: A county-level analysis. American Journal of Agricultural Economics 83 (4): 1010-23.

Hallberg, M., J. Findeis, and D. Lass. 1991. Multiple job holding among farm families. Ames, IA: Iowa State University Press.

Hanson, G., B. F. Stanton, and M. C. Ahearn. 1989. Alternative measures of farm output to classify farms by size. U.S. Department of Agriculture, Economic Research Service Technical Bulletin No. 1749.

Hopenhayn, H. 1992. Entry, exit, and firm dynamics in long-run equilibrium. Econometrica 60 (5): 1127-50.

Hoppe, R., and P. Korb. 2005. Understanding U.S. farm exits. U.S. Department of Agriculture Economic Research Report No. 21.

Jovanovic, B. 1982. Selection and the evolution of industry. Econometrica 50 (3): 649-70.

Kimhi, A., and R. Bollman. 1999. Family farm dynamics in Canada and Israel: The case of farm exits. Agricultural Economics 21 (1): 69-79.

Lambson, V. 1991. Industry evolution with sunk costs and uncertain market conditions. International Journal of Industrial Organization 9 (2): 171-96.

Levins, R. 2003. Willard Cochrane and the american family farm. Lincoln, NE: University of Nebraska Press.

Mishra, A., and B. Goodwin. 1997. Farm income variability and the supply of off farm labor. American Journal of Agricultural Economics 79 (3): 880-87.

Schumpeter, J. A. 1934. Theory of economic development. Cambridge, MA: Harvard University Press.

Stanton, B. F., J. Jinkins, M. C. Ahearn, and G. Hanson. 1992. Perspectives on farm size and structure provided by value-added measures. Journal of Agricultural Economic Research 44 (2): 36-44.

Strauss, J. 1986. The theory and comparative statics of agricultural household models: A general approach. Agricultural household models: Extensions, applica- 
tions, and policy, In I. Singh, L. Squire, and J. Strauss, eds. 71-94. Baltimore, MD: Johns Hopkins University Press.

Sumner, D., and C. Wolf. 2002. Diversification, vertical integration, and the regional pattern of dairy farm size. Review of Agricultural Economics 24 (2): 442-57.

U.S. Department of Agriculture. 2004a. Agricultural Resource Management Survey Economic Research Service. (ARMS) Briefing Room. Available at http:// www.ers.usda.gov/Briefing/ARMS/

2004b. 2002 Census of Agriculture. Vol. 1, Geographic Area Series, U.S. and State Report, http://www.agcensus.usda.gov/Publications/2002/Volume_1, _Chapter_1_US/CenV1US1.tx

. 2004c. Characteristics and Production Costs. Economic Research Service, Statistical Bulletin No. SB974. Available at http://www.ers.usda.gov/publications/ sb974/

Wu, H. 1997. An analysis of the farming decision: To farm full-time, part-time, or to exit farming. Academia Economic Papers 25 (1): 1-19.

Yee, J., and M. Ahearn. 2005. Government policies and farm size: Does the size concept matter? Applied Economics 37 (19): 2231-38.

\section{Comment Spiro E. Stefanou}

Ahearn, Korb, and Yee (AKY) embark on an interesting and challenging task in the first attempt to assemble and characterize a panel of farms using the U.S. Census of Agriculture. The authors undertake the goal of starting to organize the data to obtain a farm-level picture of the evolution of the farm size and structure. The measure of the agricultural activity is presented in terms of number of farms, average farm size, and value of farm activity over the panel. The period of focus, 1978 to 1997, is arguably the most interesting and relevant for measuring farming activity. The decline in the number of farms from over 5.65 million in 1950 had leveled off to just over 2 million by the beginning of the panel where it still hovers. The policy focus in the last quarter of the twentieth century has been on the restructuring and organization of agricultural production.

Ahearn, Korb, and Yee (AKY) note the challenges with matching up the farm as a manufacturer with the manufacturing plants found in the Census of Manufacturing. The starkest contrast is with the arbitrary and static definition of a farm as an entity tied to a parcel of land that from which at least $\$ 1,000$ of agricultural products were produced and sold (could have been sold) during the census year. The case can be made that the differences between agricultural commodity production (farm firms) and manufacturing production units (nonfarm firms) involve both broad and subtle differences. An analysis of producer dynamics in agriculture needs to reflect on these differences. 